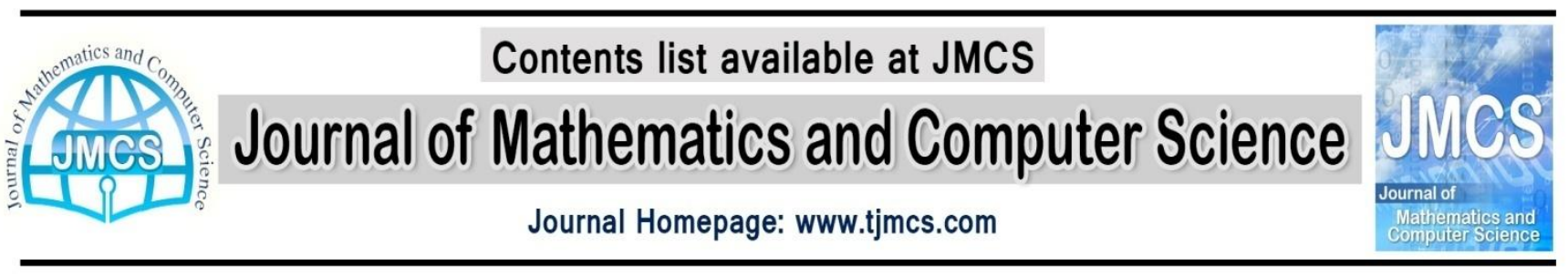

\title{
Fuzzy semi open soft sets related properties in fuzzy soft topological spaces
}

\author{
A. Kandil ${ }^{a}$, O. A. E. Tantawy $^{b}$, S. A. El-Sheikh ${ }^{c}$, A. M. Abd El-latif ${ }^{c}$ \\ ${ }^{a}$ Mathematics Department, Faculty of Science, Helwan University, Helwan, Egypt. \\ dr.ali_kandil@yahoo.com \\ ${ }^{b}$ Mathematics Department, Faculty of Science, Zagazig University, Zagazig, Egypt. \\ drosamat@yahoo.com \\ ${ }^{c}$ Mathematics Department, Faculty of Education, Ain Shams University, Cairo, Egypt. \\ sobhyelsheikh@yahoo.com,Alaa_8560@yahoo.com
}

Article history:

Received August 2014

Accepted September 2014

Available online September 2014

\begin{abstract}
In the present paper, we continue the study on fuzzy soft topological spaces and investigate the properties of fuzzy semi open (closed) soft sets, fuzzy semi soft interior (closure), fuzzy semi continuous (open) soft functions and fuzzy semi separation axioms which are important for further research on fuzzy soft topology. In particular, we study the relationship between fuzzy semi soft interior fuzzy semi soft closure. Moreover, we study the properties of fuzzy soft semi regular spaces and fuzzy soft semi normal spaces. This paper, not only can form the theoretical basis for further applications of topology on soft sets, but also lead to the development of information systems.
\end{abstract}

Keywords: Soft set, Fuzzy soft set, Fuzzy soft topological space, Fuzzy semi soft interior, Fuzzy semi soft closure, Fuzzy semi open soft, Fuzzy semi closed soft, Fuzzy semi continuous soft functions, Fuzzy soft semi separation axioms, Fuzzy soft semi $T_{i}$-spaces $(i=1,2,3,4)$, Fuzzy soft semi regular, Fuzzy soft semi normal.

\section{Introduction}

The concept of soft sets was first introduced by Molodtsov [25] in 1999 as a general mathematical tool for dealing with uncertain objects. In [25, 26], Molodtsov successfully applied the soft theory in several directions, such as smoothness of functions, game theory, operations research, Riemann integration, Perron integration, probability, theory 
of measurement, and so on. After presentation of the operations of soft sets [23], the properties and applications of soft set theory have been studied increasingly $[4,18,26]$. Xiao et al.[37] and Pei and Miao [29] discussed the relationship between soft sets and information systems. They showed that soft sets are a class of special information systems. In recent years, many interesting applications of soft set theory have been expanded by embedding the ideas of fuzzy sets $[1,6,9,13,21,22,23,24,26,27,40]$. To develop soft set theory, the operations of the soft sets are redefined and a uni-int decision making method was constructed by using these new operations [10].

Recently, in 2011, Shabir and Naz [33] initiated the study of soft topological spaces. They defined soft topology on the collection $\tau$ of soft sets over $X$. Consequently, they defined basic notions of soft topological spaces such as open soft and closed soft sets, soft subspace, soft closure, soft nbd of a point, soft separation axioms, soft regular spaces and soft normal spaces and established their several properties. Min in [36] investigate some properties of these soft separation axioms. Kandil et al. [17] introduce the notion of soft semi separation axioms. In particular they study the properties of the soft semi regular spaces and soft semi normal spaces. Maji et. al. [21] initiated the study involving both fuzzy sets and soft sets. In [8], the notion of fuzzy set soft set was introduced as a fuzzy generalization of soft sets and some basic properties of fuzzy soft sets are discussed in detail. Then many scientists such as X. Yang et. al. [38], improved the concept of fuzziness of soft sets. In [1,2], Karal and Ahmed defined the notion of a mapping on classes of (fuzzy) soft sets, which is fundamental important in (fuzzy) soft set theory, to improve this work and they studied properties of (fuzzy) soft images and (fuzzy) soft inverse image s of fuzzy soft sets. Tanay et.al. [35] introduced the definition of fuzzy soft topology over a subset of the initial universe set while Roy and Samanta [32] gave the definition $f$ fuzzy soft topology over the initial universe set. Chang [11] introduced the concept of fuzzy topology $\tau$ on a set $X$ by axiomatizing a collection of fuzzy subsets of $X$.

In the present paper, we introduce the some new concepts in fuzzy soft topological spaces such as fuzzy semi open soft sets, fuzzy semi closed soft sets, fuzzy semi soft interior, fuzzy semi soft closure and fuzzy semi separation axioms. In particular we study the relationship between fuzzy semi soft interior fuzzy semi soft closure. Also, we study the properties of fuzzy soft semi regular spaces and fuzzy soft semi normal spaces. Moreover, we show that if every fuzzy soft point $f_{e}$ is fuzzy semi closed soft set in a fuzzy soft topological space $(X, \tau, E)$, then $(X, \tau, E)$, is fuzzy soft semi $T_{1}$-space (resp. fuzzy soft semi $T_{2}$-space). This paper, not only can form the theoretical basis for further applications of topology on soft sets, but also lead to the development of information systems.

\section{Preliminaries}

In this section, we present the basic definitions and results of soft set theory which will be needed in the sequel. For more details see $[1,4,5,8,11,12,14,21,22,23,24,26,27,30,40]$. 
Definition 2.1 [39] A fuzzy set $A$ of a non-empty set $X$ is characterized by a membership function $\mu_{A}: X \rightarrow[0,1]=I$ whose value $\mu_{A}(x)$ represents the "degree of membership" of $x$ in $A$ for $x \in X$. Let $I^{X}$ denotes the family of all fuzzy sets on $X$. If $A, B \in I^{X}$, then some basic set operations for fuzzy sets are given by Zadeh [39], as follows:

1- $A \leq B \Leftrightarrow \mu_{A}(x) \leq \mu_{B}(x) \forall x \in X$.

2- $A=B \Leftrightarrow \mu_{A}(x)=\mu_{B}(x) \forall x \in X$.

3- $C=A \vee B \Leftrightarrow \mu_{C}(x)=\mu_{A}(x) \vee \mu_{B}(x) \forall x \in X$.

4- $D=A \wedge B \Leftrightarrow \mu_{D}(x)=\mu_{A}(x) \wedge \mu_{B}(x) \forall x \in X$.

5- $M=A^{\prime} \Leftrightarrow \mu_{M}(x)=1-\mu_{A}(x) \forall x \in X$.

Definition 2.2 [25] Let $X$ be an initial universe and $E$ be a set of parameters.

Let $P(X)$ denote the power set of $X$ and $A$ be a non-empty subset of $E$. A pair $(F, A)$ denoted by $F_{A}$ is called a soft set over $X$, where $F$ is a mapping given by $F: A \rightarrow P(X)$. In other words, a soft set over $X$ is a parametrized family of subsets of the universe $X$. For a particular $e \in A, F(e)$ may be considered the set of $e$-approximate elements of the soft set $(F, A)$ and if $e \notin A$, then $F(e)=\phi$ i.e $F_{A}=\{F(e): e \in A \subseteq E, F: A \rightarrow P(X)\}$. The family of all these soft sets over $X$ denoted by $S S(X)_{A}$.

Definition 2.3 [20] The union of two soft sets $(F, A)$ and $(G, B)$ over the common universe $X$ is the soft set $(H, C)$, where $C=A \cup B$ and for all $e \in C$, $H(e)=\left\{\begin{array}{l}F(e), e \in A-B, \\ G(e), e \in B-A, \\ F(e) \cup G(e), e \in A \cap B .\end{array}\right.$

Definition 2.4 [23] The intersection of two soft sets $(F, A)$ and $(G, B)$ over the common universe $X$ is the soft set $(H, C)$, where $C=A \cap B$ and for all $e \in C$, $H(e)=F(e) \cap G(e)$. Note that, in order to efficiently discuss, we consider only soft sets $(F, E)$ over a universe $X$ with the same set of parameter $E$. We denote the family of these soft sets by $S S(X)_{E}$.

Definition 2.5 [33] Let $\tau$ be a collection of soft sets over a universe $X$ with a fixed set of parameters $E$, then $\tau \subseteq S S(X)_{E}$ is called a soft topology on $X$ if; 1- $\tilde{X}, \tilde{\phi} \in \tau$, where $\tilde{\phi}(e)=\phi$ and $\tilde{X}(e)=X, \forall e \in E$, 2-the union of any number of soft sets in $\tau$ belongs to $\tau$, 3-the intersection of any two soft sets in $\tau$ belongs to $\tau$. The triplet $(X, \tau, E)$ is called a soft topological space over $X$. 
Definition 2.6 [21] Let $A \subseteq E$. A pair $(f, A)$, denoted by $f_{A}$, is called fuzzy soft set over $X$, where $f$ is a mapping given by $f: A \rightarrow I^{X}$ defined by $f_{A}(e)=\mu_{f_{A}}^{e}$, where $\mu_{f_{A}}^{e}=\overline{0}$ if $e \notin A$ and $\mu_{f_{A}}^{e} \neq \overline{0}$ if $e \in A$, where $\overline{0}(x)=0 \forall x \in X$. The family of all these fuzzy soft sets over $X$ denoted by $\operatorname{FSS}(X)_{A}$.

Proposition 2.1 [11] Every fuzzy set may be considered a soft set.

Definition 2.7 [31] The complement of a fuzzy soft set $(f, A)$, denoted by $(f, A)^{\prime}$, is defined by $(f, A)^{\prime}=\left(f^{\prime}, A\right), f_{A}^{\prime}: E \rightarrow I^{X}$ is a mapping given by $\mu_{f_{A}^{\prime}}^{e}=\overline{1}-\mu_{f_{A}}^{e} \forall e \in A$, where $\overline{1}(x)=1 \forall x \in X$. Clearly, $\left(f_{A}^{\prime}\right)^{\prime}=f_{A}$.

Definition 2.8 [23] A fuzzy soft set $f_{A}$ over $X$ is said to be a NULL fuzzy soft set, denoted by $\tilde{0}_{A}$, if for all $e \in A, f_{A}(e)=\overline{0}$.

Definition 2.9 [23] A fuzzy soft set $f_{A}$ over $X$ is said to be an absolute fuzzy soft set, denoted by $\tilde{1}_{A}$, if for all $e \in A, f_{A}(e)=\overline{1}$. Clearly we have $\left(\tilde{1}_{A}\right)^{\prime}=\tilde{0}_{A}$ and $\left(\tilde{0}_{A}\right)^{\prime}=\tilde{1}_{A}$.

Definition 2.10 [31] Let $f_{A}, g_{B} \in F S S(X)_{E}$. Then $f_{A}$ is fuzzy soft subset of $g_{B}$, denoted by $f_{A} \mid g_{B}$, if $A \subseteq B$ and $\mu_{f_{A}}^{e} \subseteq \mu_{g_{B}}^{e} \forall e \in A$, i.e.

$\mu_{f_{A}}^{e}(x) \leq \mu_{g_{B}}^{e}(x) \forall x \in X$ and $\forall e \in A$.

Definition 2.11 [31] The union of two fuzzy soft sets $f_{A}$ and $g_{B}$ over the common universe $X$ is also a fuzzy soft set $h_{C}$, where $C=A \cup B$ and for all $e \in C$, $h_{C}(e)=\mu_{h_{C}}^{e}=\mu_{f_{A}}^{e} \vee \mu_{g_{B}}^{e} \forall e \in E$. Here we write $h_{C}=f_{A} \int g_{B}$.

Definition 2.12 [31] The intersection of two fuzzy soft sets $f_{A}$ and $g_{B}$ over the common universe $X$ is also a fuzzy soft set $h_{C}$, where $C=A \cap B$ and for all $e \in C$, $h_{C}(e)=\mu_{h_{c}}^{e}=\mu_{f_{A}}^{e} \wedge \mu_{g_{B}}^{e} \forall e \in E$. Here we write $h_{C}=f_{A} \int_{g_{B}}$.

Theorem $2.1[1]$ Let $\left\{(f, A)_{j}: j \in J\right\} \subseteq F S S(X)_{E}$. Then the following statements hold, 1- $\left[\int_{j \in J}(f, A)_{j}\right]^{\prime}=\int_{j \in J}(f, A)_{j}^{\prime}$,

2- $\left[\int_{j \in J}(f, A)_{j}\right]^{\prime}=\int_{j \in J}(f, A)_{j}^{\prime}$.

Definition 2.13 [31] Let $\mathrm{T}$ be a collection of fuzzy soft sets over a universe $X$ with a fixed set of parameters $E$, then $\mathrm{T} \subseteq F S S(X)_{E}$ is called fuzzy soft topology on $X$ if 1- $\tilde{1}_{E}, \tilde{0}_{E} \in \mathrm{T}$, where $\tilde{0}_{E}(e)=\overline{0}$ and $\tilde{1}_{E}(e)=\overline{1}, \forall e \in E$, 2-the union of any members of $T$ belongs to $T$. 
3-the intersection of any two members of $T$ belongs to $T$.

The triplet $(X, \mathrm{~T}, E)$ is called fuzzy soft topological space over $X$. Also, each member of $\mathrm{T}$ is called fuzzy open soft in $(X, \mathrm{~T}, E)$. We denote the set of all open soft sets by $F O S(X, \mathrm{~T}, E)$, or $F O S(X)$ and the set of all fuzzy closed soft sets by $F C S(X, \mathrm{~T}, E)$, or $F C S(X)$.

Definition 2.14 [31] Let $(X, \mathrm{~T}, E)$ be a fuzzy soft topological space. A fuzzy soft set $f_{A}$ over $X$ is said to be fuzzy closed soft set in $X$, if its relative complement $f_{A}^{\prime}$ is fuzzy open soft set.

Definition 2.15 [28] Let $(X, \mathrm{~T}, E)$ be a fuzzy soft topological space and $f_{A} \in F S S(X)_{E}$. 1- The fuzzy soft closure of $f_{A}$, denoted by $F c l\left(f_{A}\right)$ is the intersection of all fuzzy closed soft super sets of $f_{A}$. i.e. $\operatorname{Fcl}\left(f_{A}\right)=\int\left\{h_{D}: h_{D}\right.$ is fuzzy closed soft set and $\left.f_{A} \mid h_{D}\right\}$.

2-The fuzzy soft interior of $g_{B}$, denoted by $\operatorname{Fint}\left(f_{A}\right)$ is the fuzzy soft union of all fuzzy open soft subsets of $f_{A}$.i.e.

Fint $\left(g_{B}\right)=\int\left\{h_{D}: h_{D}\right.$ is fuzzy open soft set and $\left.h_{D} \mid g_{B}\right\}$.

Definition 2.16 [20] The fuzzy soft set $f_{A} \in F S S(X)_{E}$ is called fuzzy soft point if there exist $x \in X$ and $e \in E$ such that $\mu_{f_{A}}^{e}(x)=\alpha \quad(0<\alpha \leq 1)$ and $\mu_{f_{A}}^{e}(y)=\overline{0}$ for each $y \in X-\{x\}$, and this fuzzy soft point is denoted by $x_{e}^{\alpha}$ or $f_{e}$.

Definition 2.17 [20] The fuzzy soft point $x_{e}^{\alpha}$ is said to be belonging to the fuzzy soft set $(g, A)$, denoted by $x_{e}^{\alpha} \tilde{\in}(g, A)$, if for the element $e \in A, \alpha \leq \mu_{g_{A}}^{e}(x)$.

Theorem 2.2 [20] Let $(X, \mathrm{~T}, E)$ be a fuzzy soft topological space and $f_{e}$ be a fuzzy soft point. Then the following properties hold:

1- If $f_{e} \tilde{\in} g_{A}$, then $f_{e} \approx g_{A}^{\prime}$;

2- $f_{e} \tilde{\in} g_{A} \downarrow f_{e}^{\prime} \tilde{\in} g_{A}^{\prime}$;

3-Every non-null fuzzy soft set $f_{A}$ can be expressed as the union of all the fuzzy soft points belonging to $f_{A}$.

Definition 2.18 [20] A fuzzy soft set $g_{B}$ in a fuzzy soft topological space $(X, \mathrm{~T}, E)$ is called fuzzy soft neighborhood of the fuzzy soft point $x_{e}^{\alpha}$ if there exists a fuzzy open soft set $h_{C}$ such that $x_{e}^{\alpha} \tilde{\in} h_{C} \mid g_{B}$. A fuzzy soft set $g_{B}$ in a fuzzy soft topological space $(X, \mathrm{~T}, E)$ is called fuzzy soft neighborhood of the soft set $f_{A}$ if there exists a fuzzy open soft set $h_{C}$ such that $f_{A}\left|h_{C}\right| g_{B}$. The fuzzy soft neighborhood system of the fuzzy soft point $x_{e}^{\alpha}$, denoted by $N_{\mathrm{T}}\left(x_{e}^{\alpha}\right)$, is the family of all its fuzzy soft 
neighborhoods.

Definition 2.19 [20] Let $(X, \mathrm{~T}, E)$ be a fuzzy soft topological space and $Y \subseteq X$. Let $h_{E}^{Y}$ be a fuzzy soft set over $(Y, E)$ such that $h_{E}^{Y}: E \rightarrow I^{Y}$ such that $h_{E}^{Y}(e)=\mu_{h_{E}^{Y}}^{e}$, $\mu_{h_{E}^{Y}}^{e}(x)=\left\{\begin{array}{l}1, x \in Y, \\ 0, x \notin Y .\end{array}\right.$

Let $\mathrm{T}_{Y}=\left\{h_{E}^{Y}\left\{g_{B}: g_{B} \in \mathrm{T}\right\}\right.$ then the fuzzy soft topology $\mathrm{T}_{Y}$ on $(Y, E)$ is called fuzzy soft subspace topology for $(Y, E)$ and $\left(Y, \mathrm{~T}_{Y}, E\right)$ is called fuzzy soft subspace of $(X, \mathrm{~T}, E)$. If $h_{E}^{Y} \in \mathrm{T}$ (resp. $h_{E}^{Y} \in \mathrm{T}^{\prime}$ ), then $\left(Y, \mathrm{~T}_{Y}, E\right)$ is called fuzzy open soft subspace (resp. fuzzy closed soft subspace) of $(X, T, E)$.

Definition 2.20 [28] Let $F S S(X)_{E}$ and $F S S(Y)_{K}$ be families of fuzzy soft sets over $X$ and $Y$, respectively. Let $u: X \rightarrow Y$ and $p: E \rightarrow K$ be mappings. Then the map $f_{p u}$ is called fuzzy soft mapping from $X$ to $Y$ and denoted by, $f_{p u}: F S S(X)_{E} \rightarrow F S S(Y)_{K}$ such that, 1- If $f_{A} \in F S S(X)_{E}$. Then the image of $f_{A}$ under the fuzzy soft mapping $f_{p u}$ is the fuzzy soft set over $Y$ defined by $f_{p u}\left(f_{A}\right)$, where $\forall k \in p(E), \forall y \in Y$,

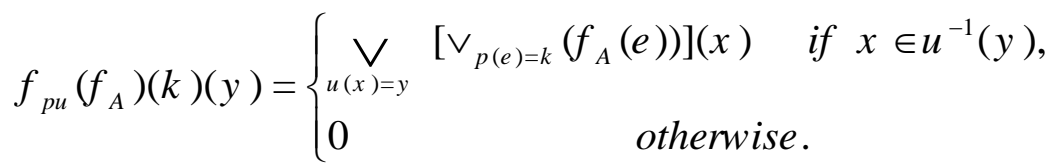

2-If $g_{B} \in F S S(Y)_{K}$, then the pre-image of $g_{B}$ under the fuzzy soft mapping $f_{p u}$ is the fuzzy soft set over $X$ defined by $f_{p u}^{-1}\left(g_{B}\right)$, where $\forall e \in p^{-1}(K), \forall x \in X$, $f^{-1}\left(g_{B}\right)(e)(x)=\left\{\begin{array}{lr}g_{B}(p(e))(u(x)) & \text { for } p(e) \in B, \\ 0 & \text { otherwise. }\end{array}\right.$

The fuzzy soft mapping $f_{p u}$ is called surjective (resp. injective) if $p$ and $u$ are surjective (resp. injective), also is said to be constant if $p$ and $u$ are constant.

Definition 2.21 [28] Let $\left(X, \mathrm{~T}_{1}, E\right)$ and $\left(Y, \mathrm{~T}_{2}, K\right)$ be two fuzzy soft topological spaces and $f_{p u}: F S S(X)_{E} \rightarrow F S S(Y)_{K}$ be a fuzzy soft mapping. Then $f_{p u}$ is called

1-Fuzzy continuous soft if $f_{p u}^{-1}\left(g_{B}\right) \in \mathrm{T}_{1} \forall\left(g_{B}\right) \in \mathrm{T}_{2}$.

2- Fuzzy open soft if $f_{p u}\left(g_{A}\right) \in \mathrm{T}_{2} \forall\left(g_{A}\right) \in \mathrm{T}_{1}$.

Theorem 2.3 [1] Let $F S S(X)_{E}$ and $F S S(Y)_{K}$ be two families of fuzzy soft sets. For the fuzzy soft function $f_{p u}: F S S(X)_{E} \rightarrow F S S(Y)_{K}$, the following statements hold, 1- $f_{p u}^{-1}\left((g, B)^{\prime}\right)=\left(f_{p u}^{-1}(g, B)\right)^{\prime} \forall(g, B) \in F S S(Y)_{K}$. 
2- $f_{p u}\left(f_{p u}^{-1}((g, B))\right) \mid(g, B) \forall(g, B) \in F S S(Y)_{K}$. If $f_{p u}$ is surjective, then the equality holds.

3- $(f, A) \hat{\text { o }} f_{p u}^{-1}\left(f_{p u}((f, A))\right) \forall(f, A) \in F S S(X)_{E}$. If $f_{p u}$ is injective, then the equality holds.

4- $f_{p u}\left(\tilde{0}_{E}\right)=\tilde{0}_{K}, f_{p u}\left(\tilde{1}_{E}\right) \hat{\text { o }} \tilde{1}_{K}$. If $f_{p u}$ is surjective, then the equality holds.

5- $f_{p u}^{-1}\left(\tilde{1}_{K}\right)=\tilde{1}_{E}$ and $f_{p u}^{-1}\left(\tilde{0}_{K}\right)=\tilde{0}_{E}$.

6- If $(f, A) \mid(g, A)$, then $f_{p u}(f, A) \mid f_{p u}(g, A)$.

7- If $(f, B) \hat{\text { o }}(g, B)$, then $f_{p u}^{-1}(f, B) \hat{\mathrm{o}} f_{p u}^{-1}(g, B) \forall(f, B),(g, B) \in F S S(Y)_{K}$.

8- $f_{p u}^{-1}\left(\int_{j \in J}(f, B)_{j}\right)=\int_{j \in J} f_{p u}^{-1}(f, B)_{j}$ and

$f_{p u}^{-1}\left(\int_{j \in J}(f, B)_{j}\right)=\int_{j \in J} f_{p u}^{-1}(f, B)_{j}, \forall(f, B)_{j} \in F S S(Y)_{K}$.

9- $f_{p u}\left(\int_{j \in J}(f, A)_{j}\right)=\int_{j \in J} f_{p u}(f, A)_{j}$ and

$f_{p u}\left(\int_{j \in J}(f, A)_{j}\right) \mid \int_{j \in J} f_{p u}(f, A)_{j} \forall(f, A)_{j} \in F S S(X)_{E}$. If $f_{p u}$ is injective, then the equality holds.

Definition 2.22 [16] Let $(X, \tau, E)$ be a soft topological space and $F_{A} \in S S(X)_{E}$. If $F_{A} \simeq \operatorname{cl}\left(\operatorname{int}\left(F_{A}\right)\right)$, then $F_{A}$ is called semi open soft set. We denote the set of all semi open soft sets by $\operatorname{SOS}(X, \tau, E)$, or $\operatorname{SOS}(X)$ and the set of all semi closed soft sets by $\operatorname{SCS}(X, \tau, E)$, or $\operatorname{SCS}(X)$.

\section{Fuzzy semi open (closed) soft sets}

Various generalization of closed and open soft sets in soft topological spaces were studied by Kandil et al. [16], but for fuzzy soft topological spaces such generalization have not been studied so far. In this section, we move one step forward to introduce fuzzy semi open and fuzzy semi closed soft sets and study various properties and notions related to these structures.

Definition 3.1 Let $(X, \mathrm{~T}, E)$ be a fuzzy soft topological space and $f_{A} \in F S S(X)_{E}$. If $f_{A} \mid \operatorname{Fcl}\left(\operatorname{Fint}\left(f_{A}\right)\right)$, then $f_{A}$ is called fuzzy semi open soft set. We denote the set of all fuzzy semi open soft sets by $F S O S(X, \mathrm{~T}, E)$, or $F S O S(X)$ and the set of all fuzzy semi closed soft sets by $\operatorname{FSCS}(X, \mathrm{~T}, E)$, or $\operatorname{FSCS}(X)$.

Theorem 3.1 Let $(X, \mathrm{~T}, E)$ be a fuzzy soft topological space and $f_{A} \in \operatorname{FSOS}(X)$. Then 1- Arbitrary fuzzy soft union of fuzzy semi open soft sets is fuzzy semi open soft.

2-Arbitrary fuzzy soft intersection of fuzzy semi closed soft sets is fuzzy semi closed soft.

Proof.

1- Let $\left\{(f, A)_{j}: j \in J\right\} \subseteq F S O S(X)$. Then $\forall j \in J,(f, A)_{j} \mid \operatorname{Fint}\left(F c l\left((f, A)_{j}\right)\right)$.

Henc, $\int_{j}(f, A)_{j}\left|\int_{j}\left(\operatorname{Fint}\left(F c l\left((f, A)_{j}\right)\right)\right)\right| \operatorname{Fint}\left(\int_{j} \operatorname{Fcl}(f, A)_{j}\right)=\operatorname{Fint}\left(F c l\left(\int_{j}(f, A)_{j}\right)\right.$. Therefore, $\int_{j}(f, A)_{j} \in F \operatorname{SOS}(X) \quad \forall j \in J$. 
2-By a similar way.

Theorem 3.2 Let $(X, \mathrm{~T}, E)$ be a fuzzy soft topological space and $f_{A} \in F S S(X)_{E}$. Then:

1- $f_{A} \in \operatorname{FSOS}(X)$ if and only if $\operatorname{Fcl}\left(f_{A}\right)=\operatorname{Fcl}\left(\operatorname{Fint}\left(f_{A}\right)\right)$.

2- If $g_{B} \in \mathrm{T}$, then $g_{B}\left(F c l\left(f_{A}\right) \mid F c l\left(g_{B}\left(g_{B}\right)\right.\right.$.

Proof. Immediate.

Theorem 3.3 Let $(X, \mathrm{~T}, E)$ be a fuzzy soft topological space and $f_{A} \in F S S(X)_{E}$. Then:

1- $f_{A} \in \operatorname{FSOS}(X)$ if and only if there exists $g_{B} \in \mathrm{T}$ such that $g_{B}$ ô $f_{A}$ ô $F c l\left(g_{B}\right)$. 2-If $f_{A} \in \operatorname{FSOS}(X)$ and $f_{A}$ ô $h_{D}$ ô $F c l\left(f_{A}\right)$, then $h_{D} \in F S O S(X)$.

\section{Proof.}

1-Let $f_{A} \in \operatorname{FSOS}(X)$. Then $f_{A}$ ô $\operatorname{Fcl}\left(\operatorname{Fint}\left(f_{A}\right)\right)$. Take $g_{B}=\operatorname{Fint}\left(f_{A}\right) \in \mathrm{T}$. So, we have $g_{B}$ ô $f_{A}$ ô $F c l\left(g_{B}\right)$. Sufficiency, let $g_{B}$ ô $f_{A}$ ô $F c l\left(g_{B}\right)$ for some $g_{B} \in \mathrm{T}$. Then $g_{B} \hat{\text { o }} \operatorname{Fint}\left(f_{A}\right)$. It follows that, $\operatorname{Fcl}\left(g_{B}\right)$ ô $\operatorname{Fcl}\left(\operatorname{Fint}\left(f_{A}\right)\right)$. Thus, $f_{A}$ ô $\operatorname{Fcl}\left(g_{B}\right)$ ô $\operatorname{Fcl}\left(\operatorname{Fint}\left(f_{A}\right)\right)$. Therefore, $f_{A} \in \operatorname{FSOS}(X)$.

2-Let $f_{A} \in \operatorname{FSOS}(X)$. Then $g_{B}$ ô $f_{A}$ ô $F C l\left(g_{B}\right)$ for some $g_{B} \in \mathrm{T}$. It follows that, $g_{B}$ ô $f_{A}$ ô $h_{D}$. Thus, $g_{B}$ ô $h_{D}$ ô $F c l\left(f_{A}\right)$ ô $F c l\left(g_{B}\right)$. Hence $g_{B}$ ô $h_{D}$ ô $F c l\left(g_{B}\right)$ for some $g_{B} \in \mathrm{T}$. Therefore, $h_{D} \in F \operatorname{SOS}(X)$ by (1).

Definition 3.2 Let $(X, \mathrm{~T}, E)$ be a fuzzy soft topological space, $f_{A} \in F S S(X)_{E}$ and $f_{e} \tilde{\in} F S S(X)_{E}$. Then

1- $f_{e}$ is called fuzzy semi interior soft point of $f_{A}$ if $\exists g_{B} \in F S O S(X)$ such that $f_{e} \tilde{\in} g_{B} \hat{\mathrm{o}} f_{A}$. The set of all fuzzy semi interior soft points of $f_{A}$ is called the fuzzy semi soft interior of $f_{A}$ and is denoted by $\operatorname{FSint}\left(f_{A}\right)$ consequently, $\operatorname{FSint}\left(f_{A}\right)=\int\left\{g_{B}: g_{B} \mid f_{A}, g_{B} \in F \operatorname{FSS}(X)\right\}$

2- $f_{e}$ is called fuzzy semi cluster soft point of $f_{A}$ if $f_{A}\left(h_{D} \neq \tilde{0}_{E} \forall h_{D} \in \operatorname{FSOS}(X)\right.$. The set of all fuzzy semi cluster soft points of $f_{A}$ is called fuzzy semi soft closure of $f_{A}$ and denoted by $\operatorname{FScl}\left(f_{A}\right)$. Consequently, $\operatorname{FScl}\left(f_{A}\right)=\left\{\left\{h_{D}: h_{D} \in \operatorname{FSCS}(X), f_{A} \mid h_{D}\right\}\right.$. Theorem 3.4 Let $(X, \mathrm{~T}, E)$ be a fuzzy soft topological space and $f_{A}, g_{B} \in F S S(X)_{E}$. Then the following properties are satisfied for the fuzzy semi interior operator, denoted by FSint .

1- $\operatorname{FSint}\left(\tilde{1}_{E}\right)=\tilde{1}_{E}$ and $\left.\operatorname{FSint}\left(\tilde{0}_{E}\right)\right)=\tilde{0}_{E}$.

2- $F \operatorname{Sint}\left(f_{A}\right) \hat{\mathrm{o}} \quad f_{A}$. 
3- $F \operatorname{Sint}\left(f_{A}\right)$ is the largest fuzzy semi open soft set contained in $f_{A}$.

4- If $f_{A} \hat{\mathrm{o}} g_{B}$, then $F \operatorname{Sint}\left(f_{A}\right) \hat{\text { o }} \operatorname{FSint}\left(g_{B}\right)$.

5- $F \operatorname{Sint}\left(F \operatorname{Sint}\left(f_{A}\right)\right)=F \operatorname{Sint}\left(f_{A}\right)$.

6- $F \operatorname{Sint}\left(f_{A}\right) \int F \operatorname{Sint}\left(g_{B}\right) \mid F \operatorname{Sint}\left[\left(f_{A}\right) \int\left(g_{B}\right)\right]$.

7- $F \operatorname{Sint}\left[\left(f_{A}\right) \int\left(g_{B}\right)\right] \mid F \operatorname{Sint}\left(f_{A}\right)\left\{F \operatorname{Sint}\left(g_{B}\right)\right.$.

Proof. Obvious.

Theorem 3.5 Let $(X, \mathrm{~T}, E)$ be a fuzzy soft topological space and $f_{A}, g_{B} \in F S S(X)_{E}$. Then the following properties are satisfied for the fuzzy semi closure operator, denoted by $\mathrm{FScl}$.

1- $\operatorname{FScl}\left(\tilde{1}_{E}\right)=\tilde{1}_{E}$ and $\operatorname{FScl}\left(\tilde{0}_{E}\right)=\tilde{0}_{E}$.

2- $\left(f_{A}\right) \mid F S c l\left(f_{A}\right)$.

3- $\operatorname{FScl}\left(f_{A}\right)$ is the smallest fuzzy semi closed soft set contains $f_{A}$.

4- If $f_{A} \mid g_{B}$, then $\operatorname{FScl}\left(f_{A}\right) \mid \operatorname{FScl}\left(g_{B}\right)$.

5- $\operatorname{FScl}\left(\operatorname{FScl}\left(f_{A}\right)\right)=\operatorname{FScl}\left(f_{A}\right)$.

6- $\operatorname{FScl}\left(f_{A}\right) \int \operatorname{FScl}\left(g_{B}\right) \mid \operatorname{FScl}\left[\left(f_{A}\right) \int\left(g_{B}\right)\right]$.

7- $\operatorname{FScl}\left[\left(f_{A}\right)\left\{\left(g_{B}\right)\right] \mid F S c l\left(f_{A}\right)\left\{\operatorname{FScl}\left(g_{B}\right)\right.\right.$.

Proof. Immediate.

Remark 3.2 Note that the family of all fuzzy semi open soft sets on a fuzzy soft topological space $(X, \mathrm{~T}, E)$ forms a fuzzy supra soft topology, which is a collection of fuzzy soft sets contains $\tilde{1}_{E}, \tilde{0}_{E}$ and closed under arbitrary fuzzy soft union.

Theorem 3.6 Every fuzzy open (resp. closed) soft set in a fuzzy soft topological space $(X, \mathrm{~T}, E)$ is fuzzy semi open (resp. fuzzy semi closed) soft.

Proof. Let $f_{A} \in \operatorname{FOS}(X)$. Then Fint $\left(f_{A}\right)=f_{A}$. Since $f_{A} \mid \operatorname{Fcl}\left(f_{A}\right)$, then $f_{A} \mid \operatorname{Fcl}\left(\operatorname{Fint}\left(f_{A}\right)\right)$. Thus, $f_{A} \in \operatorname{FSOS}(X)$.

Remark 3.3 The converse of Theorem 3.6 is not true in general as shown in the following example.

Example 3.1 Let $X=\{a, b, c\}, E=\left\{e_{1}, e_{2}, e_{3}\right\}$ and $A, B, C, D \subseteq E$ where $A=\left\{e_{1}, e_{2}\right\}$, $B=\left\{e_{2}, e_{3}\right\}, C=\left\{e_{1}, e_{3}\right\}$ and $D=\left\{e_{2}\right\}$. Let $\mathrm{T}=\left\{\tilde{1}_{E}, \tilde{0}_{E}, f_{1 A}, f_{2 B}, f_{3 D}, f_{4 E}, f_{5 B}, f_{6 D}\right\}$ where $f_{1 A}, f_{2 B}, f_{3 D}, f_{4 E}, f_{5 B}, f_{6 D}$ are fuzzy soft sets over $X$ defined as follows:

$$
\begin{aligned}
& \mu_{f_{1 A}}^{e_{1}}=\left\{a_{0.5}, b_{0.75}, c_{0.4}\right\}, \mu_{f_{1 A}}^{e_{2}}=\left\{a_{0.3}, b_{0.8}, c_{0.7}\right\}, \\
& \mu_{f_{2 B}}^{e_{2}}=\left\{a_{0.4}, b_{0.6}, c_{0.3}\right\}, \mu_{f_{2 B}}^{e_{3}}=\left\{a_{0.2}, b_{0.4}, c_{0.45}\right\}, \\
& \mu_{f_{3 D}}^{e_{2}}=\left\{a_{0.3}, b_{0.6}, c_{0.3}\right\}, \\
& \mu_{f_{4 E}}^{e_{1}}=\left\{a_{0.5}, b_{0.75}, c_{0.4}\right\}, \mu_{f_{4 E}}^{e_{2}}=\left\{a_{0.4}, b_{0.8}, c_{0.7}\right\}, \quad \mu_{f_{4 E}}^{e_{3}}=\left\{a_{0}, b_{0}, c_{0} .\right\},
\end{aligned}
$$




$$
\begin{aligned}
\mu_{f_{5 B}}^{e_{2}} & =\left\{a_{0.4}, b_{0.8}, c_{0.7}\right\}, \mu_{f_{5 B}}^{e_{3}}=\left\{a_{0.2}, b_{0.4}, c_{0.45}\right\}, \\
\mu_{f_{6 D}}^{e_{2}} & =\left\{a_{0.3}, b_{0.8}, c_{0.7}\right\} .
\end{aligned}
$$

Then $\mathrm{T}$ defines a fuzzy soft topology on $X$. Hence, the fuzzy soft set $k_{E}$ where: $\mu_{k_{E}}^{e_{1}}=\left\{a_{0.4}, b_{0.3}, c_{0.2}\right\}, \mu_{k_{E}}^{e_{2}}=\left\{a_{0.6}, b_{0.9}, c_{0.7}\right\}, \mu_{k_{E}}^{e_{3}}=\left\{a_{0.2}, b_{0.3}, c_{0.1}\right\}$.

is fuzzy semi open soft set of $(X, \mathrm{~T}, E)$, but it is not fuzzy open soft.

Theorem 3.7 Let $(X, \mathrm{~T}, E)$ be a fuzzy soft topological space and $f_{A} \in F S S(X)$. Then:

1- $\operatorname{FSint}\left(f_{A}^{\prime}\right)=\tilde{1}-\left[\operatorname{FSCl}\left(f_{A}\right)\right]$.

2- $\operatorname{FScl}\left(f_{A}^{\prime}\right)=\tilde{1}-\left[\operatorname{FSint}\left(f_{A}\right)\right]$.

\section{Proof.}

1- Let $f_{e} \notin \operatorname{FScl}\left(f_{A}\right)$. Then $\exists g_{B} \in \operatorname{FOS}\left(\tilde{1}, f_{e}\right)$ such that $g_{B}\left(f_{A}=\tilde{0}_{E}\right.$. Hence $f_{e} \tilde{\in} g_{B} \mid f_{A}^{\prime}$. Thus, $f_{e} \tilde{\in} \operatorname{FSint}\left(f_{A}^{\prime}\right)$. This means that, $\tilde{1}_{E}-F \operatorname{Scl}\left(f_{A}\right) \mid F \operatorname{Sint}\left(f_{A}^{\prime}\right)$. Conversely, Let $f_{e} \tilde{\in} \operatorname{FSint}\left(f_{A}^{\prime}\right)$. Since $\operatorname{FSint}\left(f_{A}^{\prime}\right)\left\{f_{A}=\tilde{0}_{E}\right.$. So, $f_{e} \notin \operatorname{FScl}\left(f_{A}\right)$. It follows that, $f_{e} \tilde{\in} \tilde{1}-\operatorname{FScl}\left(f_{A}\right)$. Therefore, $\operatorname{FSint}\left(f_{A}^{\prime}\right) \mid \tilde{1}-\operatorname{FScl}\left(f_{A}\right)$, and hence $\operatorname{FSint}\left(f_{A}^{\prime}\right)=\tilde{1}-\left[\operatorname{FScl}\left(f_{A}\right)\right]$.

2- Let $f_{e} \tilde{\in} F \operatorname{Sint}\left(f_{A}\right)$. Then $\forall \quad g_{B} \in F S O\left(\tilde{1}, f_{e}\right), f_{e} \tilde{\in} g_{B} \mid f_{A}$. Hence $g_{B}\left(f_{A}^{\prime}=\tilde{0}_{E}\right.$. Thus, $f_{e} \notin F \operatorname{Sint}\left(f_{A}^{\prime}\right)$. This means that, $\tilde{1}_{E}-F \operatorname{Sint}\left(f_{A}\right) \mid F \operatorname{Scl}\left(f_{A}^{\prime}\right)$. Conversely, let $f_{e} \notin \operatorname{FScl}\left(f_{A}^{\prime}\right)$. Then $\exists g_{B} \in \operatorname{FOS}\left(\tilde{1}_{E}, f_{e}\right)$ such that $g_{B}\left(f_{A}^{\prime}=\tilde{0}_{E}\right.$ Hence $f_{e} \tilde{\in} g_{B} \mid f_{A}$. It follows that, $f_{e} \tilde{\in} \operatorname{FSint}\left(f_{A}\right)$. This means that, $F \operatorname{SCl}\left(f_{A}^{\prime}\right) \mid \tilde{1}_{E}-F \operatorname{Sint}\left(f_{A}\right)$ and hence $\operatorname{FScl}\left(f_{A}^{\prime}\right)=\tilde{1}_{E}-\left[F \operatorname{Sint}\left(f_{A}\right)\right]$. This completes the proof.

Theorem 3.8 Let $(X, \mathrm{~T}, E)$ be a fuzzy soft topological space and $f_{A}, g_{B} \in F S S(X)_{E}$. If either $f_{A} \in F S O S(X)$ or $g_{B} \in F S O S(X)$. Then $\operatorname{Fint}\left(\operatorname{Fcl}\left(f_{A}\left(g_{B}\right)\right)=\operatorname{Fint}\left(F c l\left(f_{A}\right)\right)\left(\operatorname{Fint}\left(F c l\left(g_{B}\right)\right)\right.\right.$.

Proof. Let $f_{A}, g_{B} \in F S S(X)_{E}$ Then, we generally have $\operatorname{Fint}\left(\operatorname{Fcl}\left(f_{A}\left(g_{B}\right)\right) \mid \operatorname{Fint}\left(\operatorname{Fcl}\left(f_{A}\right)\right)\left(\operatorname{Fint}\left(\operatorname{Fcl}\left(f_{A}\right)\right)\right.\right.$. Suppose that $f_{A} \in \operatorname{FSOS}(X)$. Then $\operatorname{Fcl}\left(f_{A}\right)=\operatorname{Fcl}\left(\operatorname{Fint}\left(f_{A}\right)\right)$ from Theorem $3.2(1)$.

$$
\begin{aligned}
& \operatorname{Fint}\left(\operatorname{Fcl}\left(f_{A}\right)\right)\left(\operatorname{Fint}\left(F c l\left(g_{B}\right)\right) \quad \mid \quad \operatorname{Fint}\left[\operatorname { F i n t } ( F c l ( f _ { A } ) ) \left(\operatorname{Fint}\left(\operatorname{Fcl}\left(g_{B}\right)\right)\right.\right.\right. \\
& =\operatorname{Fint}\left[\operatorname{Fcl}\left(\operatorname{Fint}\left(f_{A}\right)\right)\left(\operatorname{Fint}\left(\operatorname{Fcl}\left(g_{B}\right)\right)\right]\right. \\
& \text { | Fint }\left(\operatorname{Fcl}\left[\operatorname{Fint}\left(f_{A}\right)\left(\operatorname{Fint}\left(F c l\left(g_{B}\right)\right)\right]\right)\right. \\
& \text { I Fint }\left(\text { Fcl (Fint }\left[\text { Fint }\left(f_{A}\right)\left(F c l\left(g_{B}\right)\right]\right)\right) \\
& \text { I Fint (Fcl (Fint } \left.\left.\left(F c l \quad\left[\operatorname{Fint}\left(f_{A}\right) \int\left(g_{B}\right)\right]\right)\right)\right) \\
& \text { I Fint }\left(F C l\left(f_{A}\left(g_{B}\right)\right)\right.
\end{aligned}
$$

from Theorem 3.2 (2). This completes the proof. 
Theorem 3.9 Let $(X, \mathrm{~T}, E)$ be a fuzzy soft topological space, $f_{A} \in F O S(X)$ and $g_{B} \in F S O S(X)$. Then $f_{A} \int_{B} \in F S O S(X)$.

Proof. Let $f_{A} \in F O S(X)$ and $g_{B} \in F S O S(X)$. Then

$f_{A}\left(g_{B} \mid \operatorname{Fint}\left(f_{A}\right)\left(\operatorname{Fcl}\left(\operatorname{Fint}\left(g_{B}\right)\right)=\operatorname{Fcl}\left(\operatorname{Fint}\left(f_{A}\right)\left(\operatorname{Fint}\left(g_{B}\right)\right)=\operatorname{Fcl}\left(\operatorname{Fint}\left(\left(f_{A}\right) \int\left(g_{B}\right)\right)\right)\right.\right.\right.$

from Theorem $3.2(2)$. Hence $f_{A} \int g_{B} \in \operatorname{FSOS}(X)$.

Theorem 3.10 Let $(X, \mathrm{~T}, E)$ be a fuzzy soft topological space and $f_{A} \in F S S(X)_{E}$. Then $f_{A} \in \operatorname{FSCS}(X)$ if and only if $\operatorname{Fint}\left(\operatorname{Fcl}\left(f_{A}\right)\right) \mid f_{A}$.

Proof. Let $f_{A} \in F S C S(X)$, then $f_{A}^{\prime}$ is fuzzy semi open soft set. This means that, $f_{A}^{\prime} \mid \operatorname{Fcl}\left(\operatorname{Fint}\left(\tilde{1}_{E}-f_{A}\right)\right)=\tilde{1}_{E}-\left(\operatorname{Fint}\left(F c l\left(f_{A}\right)\right)\right)$. Therefore, $\operatorname{Fint}\left(F c l\left(f_{A}\right)\right) \mid f_{A}$.

Conversely, let $\operatorname{Fint}\left(F c l\left(f_{A}\right)\right) \hat{\mathrm{o}} f_{A}$. Then $\tilde{1}_{E}-f_{A} \hat{\mathrm{o}} F \operatorname{cl}\left(\operatorname{Fint}\left(\tilde{1}_{E}-f_{A}\right)\right)$. Hence, $\tilde{1}_{E}-f_{A}$ is fuzzy semi open soft set. Therefore, $f_{A}$ is fuzzy semi closed soft set.

Corollary 3.1 Let $(X, \mathrm{~T}, E)$ be a fuzzy soft topological space and $f_{A} \in F S S(X)_{E}$. Then $f_{A} \in \operatorname{FSCS}(X)$ if and only if $f_{A}=f_{A} \int \operatorname{Fint}\left(\operatorname{Fcl}\left(f_{A}\right)\right)$.

Proof. It is obvious from Theorem 3.10.

\section{Fuzzy semi continuous soft functions}

Kharal et al. [1,2] introduced soft function over classes of (fuzzy) soft sets. The authors also defined and studied the properties of soft images and soft inverse images of (fuzzy) soft sets, and used these notions to the problem of medical diagnosis in medical expert systems. Kandil et al. [17] introduced some types of soft function in soft topological spaces. Here we introduce the notions of fuzzy semi soft function in fuzzy soft topological spaces and study its basic properties.

Definition 4.1 Let $\left(X, \mathrm{~T}_{1}, E\right),\left(Y, \mathrm{~T}_{2}, K\right)$ be fuzzy soft topological spaces and $f_{p u}: F S S(X)_{E} \rightarrow F S S(Y)_{K}$ be a soft function. Then $f_{p u}$ is called;

1- Fuzzy semi continuous soft function if $f_{p u}^{-1}\left(g_{B}\right) \in F S O S(X) \forall g_{B} \in \mathrm{T}_{2}$.

2- Fuzzy fuzzy semi open soft if $f_{p u}\left(g_{A}\right) \in \operatorname{FSOS}(Y) \forall g_{A} \in \mathrm{T}_{1}$.

3- Fuzzy semi closed soft if $f_{p u}\left(f_{A}\right) \in \operatorname{FSCS}(Y) \forall f_{A} \in \mathrm{T}^{\prime}{ }_{1}$.

4- Fuzzy irresolute soft if $f_{p u}^{-1}\left(g_{B}\right) \in F S O S(X) \forall g_{B} \in F S O S(Y)$.

5- Fuzzy irresolute open soft if $f_{p u}\left(g_{A}\right) \in \operatorname{FSOS}(Y) \forall g_{A} \in F S O S(X)$.

6- Fuzzy irresolute closed soft if $f_{p u}\left(f_{A}\right) \in \operatorname{FSCS}(Y) \forall f_{A} \in \operatorname{FSCS}(Y)$.

Example 4.1 Let $X=Y=\{a, b, c\}, E=\left\{e_{1}, e_{2}, e_{3}\right\}$ and $A \subseteq E$ where $A=\left\{e_{1}, e_{2}\right\}$. Let $f_{p u}:\left(X, \mathrm{~T}_{1}, E\right) \rightarrow\left(Y, \mathrm{~T}_{2}, K\right)$ be the constant soft mapping where $\mathrm{T}_{1}$ is the indiscrete fuzzy soft topology and $\mathrm{T}_{2}$ is the discrete fuzzy soft topology such that $u(x)=a \forall x \in X$ and $p(e)=e_{1} \forall e \in E$. Let $f_{A}$ be fuzzy soft sets over $Y$ defined as follows: 
$\mu_{f_{A}}^{e_{1}}=\left\{a_{0.1}, b_{0.5}, c_{6}\right\}, \mu_{f_{A}}^{e_{2}}=\left\{a_{0.6}, b_{0.2}, c_{0.5}\right\}$.

Then $f_{A} \in \mathrm{T}_{2}$. Now, we find $f_{p u}^{-1}\left(f_{A}\right)$ as follows:

$f_{p u}^{-1}\left(f_{A}\right)\left(e_{1}\right)(a)=f_{A}\left(p\left(e_{1}\right)\right)(u(a))=f_{A}\left(e_{1}\right)(a)=0.1$,

$f_{p u}^{-1}\left(f_{A}\right)\left(e_{1}\right)(b)=f_{A}\left(p\left(e_{1}\right)\right)(u(b))=f_{A}\left(e_{1}\right)(a)=0.1$,

$f_{p u}^{-1}\left(f_{A}\right)\left(e_{1}\right)(c)=f_{A}\left(p\left(e_{1}\right)\right)(u(c))=f_{A}\left(e_{1}\right)(a)=0.1$,

$f_{p u}^{-1}\left(f_{A}\right)\left(e_{2}\right)(a)=f_{A}\left(p\left(e_{2}\right)\right)(u(a))=f_{A}\left(e_{1}\right)(a)=0.1$,

$f_{p u}^{-1}\left(f_{A}\right)\left(e_{2}\right)(b)=f_{A}\left(p\left(e_{2}\right)\right)(u(b))=f_{A}\left(e_{1}\right)(a)=0.1$,

$f_{p u}^{-1}\left(f_{A}\right)\left(e_{2}\right)(c)=f_{A}\left(p\left(e_{2}\right)\right)(u(c))=f_{A}\left(e_{1}\right)(a)=0.1$,

$f_{p u}^{-1}\left(f_{A}\right)\left(e_{3}\right)(a)=f_{A}\left(p\left(e_{3}\right)\right)(u(a))=f_{A}\left(e_{1}\right)(a)=0.1$,

$f_{p u}^{-1}\left(f_{A}\right)\left(e_{3}\right)(b)=f_{A}\left(p\left(e_{3}\right)\right)(u(b))=f_{A}\left(e_{1}\right)(a)=0.1$,

$f_{p u}^{-1}\left(f_{A}\right)\left(e_{3}\right)(c)=f_{A}\left(p\left(e_{3}\right)\right)(u(c))=f_{A}\left(e_{1}\right)(a)=0.1$.

Hence $f_{p u}^{-1}\left(f_{A}\right) \notin F S O S(X)$. Therefore, $f_{p u}$ is not fuzzy semi continuous soft function.

Theorem 4.1 Every fuzzy continuous soft function is fuzzy semi continuous soft.

Proof. It is obvious from Theorem 3.6.

Theorem 4.2 Let $\left(X, \mathrm{~T}_{1}, E\right),\left(Y, \mathrm{~T}_{2}, K\right)$ be fuzzy soft topological spaces and $f_{p u}$ be a soft function such that $f_{p u}: F S S(X)_{E} \rightarrow F S S(Y)_{K}$. Then the following are equivalent:

1- $f_{p u}$ is fuzzy semi continuous soft function.

2- $f_{p u}^{-1}\left(h_{B}\right) \in \operatorname{FSCS}(X) \forall h_{B} \in F C S(Y)$.

3- $f_{p u}\left(F S c l\left(g_{A}\right) \mid F c l_{\mathrm{T}_{2}}\left(f_{p u}\left(g_{A}\right)\right) \forall g_{A} \in F S S(X)_{E}\right.$.

4- $\operatorname{FScl}\left(f_{p u}^{-1}\left(h_{B}\right)\right) \mid f_{p u}^{-1}\left(F S c l_{\mathrm{T}_{2}}\left(h_{B}\right)\right) \forall h_{B} \in F S S(Y)_{K}$.

5- $f_{p u}^{-1}\left(\operatorname{Fint}_{\mathrm{T}_{2}}\left(h_{B}\right)\right) \mid \operatorname{FSint}\left(f_{p u}^{-1}\left(h_{B}\right)\right) \forall h_{B} \in F S S(Y)_{K}$.

\section{Proof.}

$1 \rightarrow \mathbf{2}$ Let $h_{B}$ be a fuzzy closed soft set over $Y$. Then $h_{B}^{\prime} \in F O S(Y)$ and $f_{p u}^{-1}\left(h_{B}^{\prime}\right) \in \operatorname{FSOS}(X)$ from Definition 4.1. Since $f_{p u}^{-1}\left(h_{B}^{\prime}\right)=\left(f_{p u}^{-1}\left(h_{B}\right)\right)^{\prime}$ from Theorem 2.3.

Thus, $f_{p u}^{-1}\left(h_{B}\right) \in \operatorname{FSCS}(X)$.

$2 \rightarrow 3$ Let $g_{A} \in F S S(X)_{E}$. Since $g_{A}\left|f_{p u}^{-1}\left(f_{p u}\left(g_{A}\right)\right)\right| f_{p u}^{-1}\left(F c l_{\mathrm{T}_{2}}\left(f_{p u}\left(g_{A}\right)\right)\right) \in F S C S(X)$ from (2) and Theorem 2.3. Then $g_{A}\left|F S c l\left(g_{A}\right)\right| f_{p u}^{-1}\left(F c l_{\mathrm{T}_{2}}\left(f_{p u}\left(g_{A}\right)\right)\right)$. Hence, $\left.f_{p u}\left(F \operatorname{Scl}\left(g_{A}\right)\right)\left|f_{p u}\left(f_{p u}^{-1}\left(F c l_{\mathrm{T}_{2}}\left(f_{p u}\left(g_{A}\right)\right)\right)\right)\right| F c l_{\mathrm{T}_{2}}\left(f_{p u}\left(g_{A}\right)\right)\right)$ from Theorem 2.3. Thus, $f_{p u}\left(F \operatorname{Scl}\left(g_{A}\right)\right) \mid F c l_{\mathrm{T}_{2}}\left(f_{p u}\left(g_{A}\right)\right)$.

$\mathbf{3} \rightarrow \mathbf{4}$ Let $h_{B} \in F S S(Y)_{K}$ and $g_{A}=f_{p u}^{-1}\left(h_{B}\right)$. Then 
$f_{p u}\left(F S c l f_{p u}^{-1}\left(h_{B}\right)\right) \mid F c l_{\mathrm{T}_{2}}\left(f_{p u}\left(f_{p u}^{-1}\left(h_{B}\right)\right)\right)$ From (3). Hence,

$\operatorname{FScl}\left(f_{p u}^{-1}\left(h_{B}\right)\right)\left|f_{p u}^{-1}\left(f_{p u}\left(F S c l\left(f_{p u}^{-1}\left(h_{B}\right)\right)\right)\right)\right| f_{p u}^{-1}\left(F c l_{\mathrm{T}_{2}}\left(f_{p u}\left(f_{p u}^{-1}\left(h_{B}\right)\right)\right)\right) \mid f_{p u}^{-1}\left(F c l_{\mathrm{T}_{2}}\left(h_{B}\right)\right)$

from Theorem 2.3. Thus, $\operatorname{FScl}\left(f_{p u}^{-1}\left(h_{B}\right)\right) \mid f_{p u}^{-1}\left(F c l_{\mathrm{T}_{2}}\left(h_{B}\right)\right)$.

$4 \rightarrow 2$ Let $h_{B}$ be a fuzzy closed soft set over $Y$. Then

$\operatorname{FScl}\left(f_{p u}^{-1}\left(h_{B}\right)\right) \mid f_{p u}^{-1}\left(F c l_{\mathrm{T}_{2}}\left(h_{B}\right)\right)=f_{p u}^{-1}\left(h_{B}\right) \quad \forall h_{B} \in F S S(Y)_{K}$ from (4). But clearly,

$f_{p u}^{-1}\left(h_{B}\right) \mid \operatorname{FScl}\left(f_{p u}^{-1}\left(h_{B}\right)\right)$. This means that, $f_{p u}^{-1}\left(h_{B}\right)=\operatorname{FScl}\left(f_{p u}^{-1}\left(h_{B}\right)\right) \in \operatorname{FSCS}(X)$.

$\mathbf{1} \rightarrow \mathbf{5}$ Let $h_{B} \in F S S(Y)_{K}$. Then, $f_{p u}^{-1}\left(\operatorname{Fint}_{\mathrm{T}_{2}}\left(h_{B}\right)\right) \in F S O S(X)$ from (1). Hence,

$f_{p u}^{-1}\left(\operatorname{Fint}_{\mathrm{T}_{2}}\left(h_{B}\right)\right)=F \operatorname{Sint}\left(f_{p u}^{-1} \operatorname{Fint}_{\mathrm{T}_{2}}\left(h_{B}\right)\right) \mid \operatorname{FSint}\left(f_{p u}^{-1}\left(h_{B}\right)\right)$. Thus,

$f_{p u}^{-1}\left(\right.$ Fint $\left._{\mathrm{T}_{2}}\left(h_{B}\right)\right) \mid \operatorname{FSint}\left(f_{p u}^{-1}\left(h_{B}\right)\right)$.

$\mathbf{5} \rightarrow \mathbf{1}$ Let $h_{B}$ be a fuzzy open soft set over $Y$. Then Fint $_{\mathrm{T}_{2}}\left(h_{B}\right)=h_{B}$ and $f_{p u}^{-1}\left(\right.$ Fint $\left._{\mathrm{T}_{2}}\left(h_{B}\right)\right)=f_{p u}^{-1}\left(\left(h_{B}\right)\right) \mid F \operatorname{Sint}\left(f_{p u}^{-1}\left(h_{B}\right)\right)$ from (5). But we have $\operatorname{FSint}\left(f_{p u}^{-1}\left(h_{B}\right)\right) \mid f_{p u}^{-1}\left(h_{B}\right)$. This means that, $\operatorname{FSint}\left(f_{p u}^{-1}\left(h_{B}\right)\right)=f_{p u}^{-1}\left(h_{B}\right) \in \operatorname{FSOS}(X)$. Thus, $f_{p u}$ is fuzzy semi continuous soft function.

Theorem 4.3 Let $\left(X, \mathrm{~T}_{1}, E\right)$ and $\left(Y, \mathrm{~T}_{2}, K\right)$ be fuzzy soft topological spaces and $f_{p u}$ be a soft function such that $f_{p u}: F S S(X)_{E} \rightarrow F S S(Y)_{K}$. Then the following are equivalent:

1- $f_{p u}$ is fuzzy semi open soft function.

2- $f_{p u}\left(\right.$ Fint $\left._{\mathrm{T}_{1}}\left(g_{A}\right)\right) \mid \operatorname{FSint}\left(f_{p u}\left(g_{A}\right)\right) \forall g_{A} \in F S S(X)_{E}$.

Proof.

$\mathbf{1} \rightarrow \mathbf{2}$ Let $g_{A} \in \mathrm{T}_{1}$. Then $f_{p u}\left(g_{A}\right) \in \operatorname{FSOS}(Y) \forall g_{A} \in \mathrm{T}_{1}$ by (1). It follow that, $f_{p u}\left(\right.$ Fint $\left._{\mathrm{T}_{1}}\left(g_{A}\right)\right)=F \operatorname{Sint}\left(f_{p u} \operatorname{Fint}_{\mathrm{T}_{1}}\left(g_{A}\right)\right) \mid F \operatorname{Sint}\left(f_{p u}\left(g_{A}\right)\right)$. Therefore, $f_{p u}\left(\right.$ Fint $\left._{\mathrm{T}_{1}}\left(g_{A}\right)\right) \mid \operatorname{FSint}\left(f_{p u}\left(g_{A}\right)\right) \forall g_{A} \in F S S(X)_{E}$.

$\mathbf{2} \rightarrow \mathbf{1}$ Let $g_{A} \in \mathrm{T}_{1}$. By hypothesis,

$f_{p u}\left(\right.$ Fint $\left._{\mathrm{T}_{1}}\left(g_{A}\right)\right)=f_{p u}\left(g_{A}\right) \mid F \operatorname{Sint}\left(f_{p u}\left(g_{A}\right)\right) \in \operatorname{FSOS}(Y)$. Then, $f_{p u}\left(g_{A}\right) \in \operatorname{FSOS}(Y) \forall g_{A} \in \mathrm{T}_{1}$. Hence, $f_{p u}$ is fuzzy semi open soft function.

Theorem 4.4 Let $f_{p u}: F S S(X)_{E} \rightarrow F S S(Y)_{K}$ be a fuzzy semi open soft function. If $k_{D} \in F S S(Y)_{K}$ and $l_{C} \in \mathrm{T}^{\prime}{ }_{1}$ such that $f_{p u}^{-1}\left(k_{D}\right) \mid l_{C}$, then there exists $h_{B} \in \operatorname{FSCS}(Y)$ such that $k_{D} \mid h_{B}$ and $f_{p u}^{-1}\left(h_{B}\right) \mid l_{C}$. 
Proof. Let $k_{D} \in F S S(Y)_{K}$ and $l_{C} \in \mathrm{T}^{\prime}{ }_{1}$ such that $f_{p u}^{-1}\left(k_{D}\right) \mid l_{C}$. Then, $f_{p u}\left(l_{C}^{\prime}\right) \mid k_{D}^{\prime}$ from Theorem 2.3 where $l_{C}^{\prime} \in \mathrm{T}_{1}$. Since $f_{p u}$ is fuzzy semi open soft function. Then $f_{p u}\left(l_{C}^{\prime}\right) \in \operatorname{FSOS}(Y)$. Take $h_{B}=\left[f_{p u}\left(l_{C}^{\prime}\right)\right]^{\prime}$. Hence $h_{B} \in F S C S(Y)$ such that $k_{D} \mid h_{B}$ and $f_{p u}^{-1}\left(h_{B}\right)=f_{p u}^{-1}\left(\left[f_{p u}\left(l_{C}^{\prime}\right)\right]^{\prime}\right)\left|f_{p u}^{-1}\left(k_{D}^{\prime}\right)^{\prime}=f_{p u}^{-1}\left(k_{D}\right)\right| l_{C}$. This completes the proof.

Theorem 4.5 Let $\left(X, \mathrm{~T}_{1}, E\right)$ and $\left(Y, \mathrm{~T}_{2}, K\right)$ be fuzzy soft topological spaces and $f_{p u}$ be a soft function such that $f_{p u}: F S S(X)_{E} \rightarrow F S S(Y)_{K}$. Then the following are equivalent:

1- $f_{p u}$ is fuzzy semi closed soft function.

2- $\operatorname{FScl}\left(f_{p u}\left(h_{A}\right)\right) \mid f_{p u}\left(F c l_{\mathrm{T}_{1}}\left(h_{A}\right)\right) \forall h_{A} \in F S S(X)_{E}$.

Proof.

$\mathbf{1} \rightarrow \mathbf{2}$ Let $h_{A} \in \mathrm{T}^{\prime}{ }_{1}$. Then $f_{p u}\left(h_{A}\right) \in \operatorname{FSCS}(Y) \forall f_{A} \in \mathrm{T}^{\prime}{ }_{1}$ by (1). Hence, $\operatorname{FScl}\left(f_{p u}\left(h_{A}\right)\right)=f_{p u}\left(h_{A}\right) \mid f_{p u}\left(F c l_{\mathrm{T}_{1}}\left(h_{A}\right)\right) \forall h_{A} \in F S S(X)_{E}$.

$\mathbf{2} \rightarrow \mathbf{1}$ Let $g_{A} \in \mathrm{T}^{\prime}{ }_{1}$. By hypothesis, $F S c l\left(f_{p u}\left(h_{A}\right)\right) \mid f_{p u}\left(F c l_{\mathrm{T}_{1}}\left(h_{A}\right)\right)=f_{p u}\left(h_{A}\right)$. Hence, $f_{p u}\left(h_{A}\right) \in \operatorname{FSCS}(Y) \forall h_{A} \in \mathrm{T}_{1}^{\prime}$. Therefore, $f_{p u}$ is fuzzy semi closed soft function.

\section{Fuzzy soft semi separation axioms}

Soft separation axioms for soft topological spaces were studied by Shabir and $\mathrm{Naz}$ [33]. Kandil et al. [17] introduced the notions of soft semi separation axioms in soft topological spaces. Here we introduce the notions of fuzzy semi connectedness in fuzzy soft topological spaces and study its basic properties.

Definition 5.1 Two fuzzy soft points $f_{e}=x_{e}^{\alpha}$ and $g_{e}=y_{e}^{\alpha}$ are said to be distinct if and only if $x \neq y$.

Definition 5.2 A fuzzy soft topological space $(X, T, E)$ is said to be a fuzzy soft semi $T_{o}$-space if for every pair of distinct fuzzy soft points $f_{e}, g_{e}$ there exists a fuzzy semi open soft set containing one but not the other.

\section{Examples 5.1}

1- Let $X=\{a, b\}, E=\left\{e_{1}, e_{2}\right\}$ and $\mathrm{T}$ be the discrete fuzzy soft topology on $X$. Then $(X, \mathrm{~T}, E)$ is fuzzy soft semi $T_{o}$-space.

2- Let $X=\{a, b\}, E=\left\{e_{1}, e_{2}\right\}$ and $\mathrm{T}$ be the indiscrete fuzzy soft topology on $X$. Then $\mathrm{T}$ is not fuzzy soft semi $T_{o}$-space.

Theorem 5.1 A soft subspace $\left(Y, \mathrm{~T}_{Y}, E\right)$ of a fuzzy soft semi $T_{o}$-space $(X, \mathrm{~T}, E)$ is fuzzy soft semi $T_{o}$.

Proof. Let $h_{e}, g_{e}$ be two distinct fuzzy soft points of $\mathrm{T}_{Y}$. Then these fuzzy soft points 
are also in $\mathrm{T}$. Hence there exists a fuzzy semi open soft set $f_{A}$ in $\mathrm{T}$ containing one fuzzy soft point but not the other. Thus, $h_{E}^{Y}\left[f_{A}\right.$ is fuzzy semi open soft set in $\left(Y, \mathrm{~T}_{Y}, E\right)$ containing one fuzzy soft point but not the other from Definition 2.19. Therefore, $\left(Y, \mathrm{~T}_{Y}, E\right)$ is fuzzy soft semi $T_{o}$.

Definition 5.3 A fuzzy soft topological space $(X, \mathrm{~T}, E)$ is said to be a fuzzy soft semi $T_{1}$-space if for every pair of distinct fuzzy soft points $f_{e}, g_{e}$ there exist fuzzy semi open soft sets $f_{A}$ and $g_{B}$ such that $f_{e} \tilde{\in} f_{A}, g_{e} \notin f_{A} ; f_{e} \notin g_{B}, g_{e} \tilde{\in} g_{B}$.

Example 5.1 Let $X=\{a, b\}, E=\left\{e_{1}, e_{2}\right\}$ and $\mathrm{T}$ be the discrete fuzzy soft topology on $X$. Then $(X, \mathrm{~T}, E)$ is fuzzy soft semi $T_{1}$-space.

Theorem 5.2 A fuzzy soft subspace $\left(Y, \mathrm{~T}_{Y}, E\right)$ of a fuzzy soft semi $T_{1}$-space $(X, \mathrm{~T}, E)$ is fuzzy soft semi $T_{1}$.

Proof. It is similar to the proof of Theorem 5.1.

Theorem 5.3 If every fuzzy soft point of a fuzzy soft topological space $(X, \mathrm{~T}, E)$ is fuzzy semi closed soft, then $(X, \mathrm{~T}, E)$ is fuzzy soft semi $T_{1}$.

Proof. Suppose that $f_{e}=x_{e_{i}}^{\alpha}$ and $g_{e}=y_{e_{j}}^{\beta} \quad(i \neq j)$ be two distinct fuzzy soft points of $\mathrm{T}$. Then we have two cases:

1. $\alpha, \beta \leq 0.5$.

Then we can always find some $\gamma, \delta$ such that $\alpha \leq \gamma$ and $\beta \leq \delta$. Hence $\alpha \leq 1-\gamma$ and $\beta \leq 1-\delta$. Thus, $x_{e_{i}}^{1-\gamma}$ and $y_{e_{j}}^{1-\delta} \quad(i \neq j)$ are two fuzzy semi open soft sets containing $x_{e_{i}}^{\alpha}$ and $y_{e_{j}}^{\beta}(i \neq j)$ respectively. Therefore, $(X, \mathrm{~T}, E)$ is fuzzy soft semi $T_{1}$.

2. $\alpha, \beta>0.5$.

Then, we can always find some $\gamma, \delta$ such that $\alpha \leq \gamma$ and $\beta \leq \delta$. Hence $\alpha \leq 1-\gamma$ and $\beta \leq 1-\delta$. Thus, $x_{e_{i}}^{1-\gamma}$ and $y_{e_{j}}^{1-\delta} \quad(i \neq j)$ are two fuzzy semi open soft sets containing $x_{e_{i}}^{\alpha}$ and $y_{e_{j}}^{\beta}(i \neq j)$ respectively. Therefore, $(X, \mathrm{~T}, E)$ is fuzzy soft semi $T_{1}$.

Definition 5.4 A fuzzy soft topological space $(X, \mathrm{~T}, E)$ is said to be a fuzzy soft semi $T_{2}$-space if for every pair of distinct fuzzy soft points $f_{e}, g_{e}$ there exist disjoint fuzzy semi open soft sets $f_{A}$ and $g_{B}$ such that $f_{e} \tilde{\in} f_{A}$ and $g_{e} \tilde{\in} g_{B}$.

Example 5.2 Let $X=\{a, b\}, E=\left\{e_{1}, e_{2}\right\}$ and $\mathrm{T}$ be the discrete fuzzy soft topology on $X$. Then $(X, \mathrm{~T}, E)$ is fuzzy soft semi $T_{2}$-space. 
Proposition 5.1 For a fuzzy soft topological space $(X, T, E)$ we have: fuzzy soft semi $T_{2}$-space $\Rightarrow$ fuzzy soft semi $T_{1}$-space $\Rightarrow$ fuzzy soft semi- $T_{o}$-space. Proof.

1-Let $(X, \mathrm{~T}, E)$ be a fuzzy soft semi $T_{2}$-space and $f_{e}, g_{e}$ be two distinct fuzzy soft points. Then, there exist disjoint fuzzy semi open soft sets $f_{A}$ and $g_{B}$ such that $f_{e} \tilde{\in} f_{A}$ and $g_{e} \tilde{\in} g_{B}$. Since $f_{A} \int_{B}=\tilde{0}_{E}$. Then $f_{e} \nsubseteq g_{B}$ and $g_{e} \nsubseteq f_{A}$. Therefore, there exist fuzzy semi open soft sets $f_{A}$ and $g_{B}$ such that $f_{e} \tilde{\in} f_{A}, g_{e} \widetilde{\notin} f_{A}$; and $f_{e} \mp g_{B}, g_{e} \tilde{\in} g_{B}$. Thus, $(X, \mathrm{~T}, E)$ is fuzzy soft semi $T_{1}$-space.

2- Let $(X, \mathrm{~T}, E)$ be a fuzzy soft semi $T_{1}$-space and $f_{e}, g_{e}$ be two distinct fuzzy soft points. Then there exist fuzzy semi open soft sets $f_{A}$ and $g_{B}$ such that $f_{e} \tilde{\in} f_{A}$, $g_{e} \nsubseteq f_{A}$; and $f_{e} f_{e} \nsubseteq g_{B}, g_{e} \tilde{\in} g_{B}$. Then we have a fuzzy semi open soft set containing one of the fuzzy soft point but not the other. Thus, $(X, T, E)$ is fuzzy soft semi $T_{o}$ -space.

Theorem 5.4 Let $(X, \mathrm{~T}, E)$ be a fuzzy soft topological space. If $(X, \mathrm{~T}, E)$ is fuzzy soft semi $T_{2}$-space, then for every pair of distinct fuzzy soft points $f_{e}, g_{e}$ there exists a fuzzy semi closed soft set $b_{A}$ such that containing one of the fuzzy soft points $g_{e} \tilde{\in} b_{A}$, but not the other $f_{e} \nsubseteq b_{A}$ and $g_{e} \nsubseteq \operatorname{FScl}\left(b_{A}\right)$.

Proof. Let $f_{e}, g_{e}$ be two distinct fuzzy soft points. By assumption, there exists a fuzzy semi open soft sets $b_{A}$ and $h_{B}$ such that $f_{e} \tilde{\in} b_{A}, g_{e} \tilde{\in} h_{B}$. Hence, $g_{e} \tilde{\in} b_{A}^{\prime}$ and $f_{e}$ $\nexists b_{A}^{\prime}$ from Theorem 2.2. Thus, $b_{A}^{\prime}$ is a fuzzy semi closed soft set containing $g_{e}$ but not $f_{e}$ and $f_{e} \mp F S c l\left(b_{A}^{\prime}\right)=b_{A}^{\prime}$.

Theorem 5.5 A fuzzy soft subspace $\left(Y, \mathrm{~T}_{Y}, E\right)$ of fuzzy soft semi $T_{2}$-space $(X, \mathrm{~T}, E)$ is fuzzy soft semi $T_{2}$.

Proof. Let $j_{e}, k_{e}$ be two distinct fuzzy soft points of $\mathrm{T}_{Y}$. Then these fuzzy soft points are also in $\mathrm{T}$. Hence there exist distinct fuzzy semi open soft sets $f_{A}$ and $g_{B}$ in $\mathrm{T}$ such that $j_{e} \in f_{A}$ and $k_{e} \in g_{B}$. Thus, $h_{E}^{Y}\left[f_{A}\right.$ and $h_{E}^{Y} \int g_{B}$ are disjoint fuzzy semi open soft sets in $\left(Y, \mathrm{~T}_{Y}, E\right)$ such that $j_{e} \in h_{E}^{Y}\left\{f_{A}\right.$ and $k_{e} \in h_{E}^{Y} \int g_{B}$. Therefore, $\left(Y, \mathrm{~T}_{Y}, E\right)$ is fuzzy sssoft semi $T_{2}$.

Theorem 5.6 If every fuzzy soft point of a fuzzy soft topological space $(X, \mathrm{~T}, E)$ is fuzzy semi closed soft, then $(X, T, E)$ is fuzzy soft semi $T_{2}$.

Proof. It similar to the proof of Theorem 5.3.

Definition 5.5 Let $(X, \mathrm{~T}, E)$ be a fuzzy soft topological space, $h_{C}$ be a fuzzy semi 
closed soft set and $g_{e}$ be a fuzzy soft point such that $g_{e} \nsubseteq h_{C}$. If there exist fuzzy semi open soft sets $f_{S}$ and $f_{W}$ such that $g_{e} \tilde{\in} f_{S}, g_{B} \mid f_{W}$ and $f_{S}\left[f_{W}=\tilde{0}_{E}\right.$, then $(X, \mathrm{~T}, E)$ is called fuzzy soft semi regular space. A fuzzy soft semi regular $T_{1}$-space is called fuzzy soft semi $T_{3}$-space.

Proposition 5.2 Let $(X, \mathrm{~T}, E)$ be a fuzzy soft topological space, $h_{C}$ be a fuzzy semi closed soft set and $g_{e}$ be a fuzzy soft point such that $g_{e} \nsubseteq h_{C}$. If $(X, \mathrm{~T}, E)$ is fuzzy soft semi regular space, then there exists a fuzzy semi open soft set $f_{A}$ such that $g_{e} \tilde{\in} f_{A}$ and $f_{A}\left(h_{C}=\tilde{0}_{E}\right.$.

Proof. Obvious from Definition 5.5.

Theorem 5.7 Let $(X, \mathrm{~T}, E)$ be a fuzzy soft semi regular space in which every fuzzy soft point is fuzzy semi closed soft. Then for a fuzzy semi open soft set $g_{B}$ containing fuzzy soft point $f_{e}$, there exists a fuzzy semi open soft set $f_{S}$ containing $f_{e}$ such that $\operatorname{FScl}\left(f_{S}\right) \mid g_{B}$.

Proof. Let $g_{B}$ be a fuzzy semi open soft set containing fuzzy soft point $f_{e}$ in a fuzzy soft semi regular space $(X, \mathrm{~T}, E)$. Then $g_{B}^{\prime}$ is fuzzy semi closed soft such that $f_{e} \mp g_{B}^{\prime}$ from Theorem 2.2. By hypothesis, there exists disjoint fuzzy semi open soft sets $f_{S}$ and $f_{W}$ such that $f_{e} \tilde{\in} f_{S}$ and $g_{B}^{\prime} \mid f_{W}$. It follows that $f_{W}^{\prime} \mid g_{B}$ and $f_{S} \mid f_{W}^{\prime}$. Thus, $\operatorname{FScl}\left(f_{S}\right)\left|f_{W}^{\prime}\right| g_{B}$. Therefore, there exists a fuzzy semi open soft set $f_{S}$ containing $f_{e}$ such that $\operatorname{FScl}\left(f_{S}\right) \mid g_{B}$.

Theorem $5.8 \mathrm{~A}$ fuzzy soft subspace $\left(Y, \mathrm{~T}_{Y}, E\right)$ of a fuzzy soft semi $T_{3}$-space $(X, \mathrm{~T}, E)$ is fuzzy soft semi $T_{3}$.

Proof. By Theorem 5.2, $\left(Y, \mathrm{~T}_{Y}, E\right)$ is fuzzy soft semi $T_{1}$-space. Now we want to prove that $\left(Y, \mathrm{~T}_{Y}, E\right)$ is fuzzy soft semi regular space. Let $k_{E}$ be a fuzzy semi closed soft set in $\mathrm{T}_{Y}$ and $g_{e}$ be a fuzzy soft point in $\mathrm{T}_{Y}$ such that $g_{e} \notin k_{E}$. Then $k_{E}$ is also fuzzy semi closed soft set in $\mathrm{T}$ and $g_{e}$ is also fuzzy soft point in $\mathrm{T}$ such that $g_{e} \notin k_{E}$. Since $(X, \mathrm{~T}, E)$ is fuzzy soft semi $T_{3}$. Then there exist disjoint fuzzy semi open soft sets $f_{S}$ and $f_{W}$ in $\mathrm{T}$ such that $g_{e} \tilde{\in} f_{S}$ and $k_{E} \mid f_{W}$. It follows that $h_{E}^{Y}\left[f_{S}\right.$ and $h_{E}^{Y}\left(f_{W}\right.$ are disjoint fuzzy semi open soft sets in $\mathrm{T}_{Y}$ such that $g_{e} \tilde{\in} h_{E}^{Y}\left(f_{S}\right.$ and $k_{E} \mid h_{E}^{Y}\left(f_{W}\right.$. Therefore, $\left(Y, \mathrm{~T}_{Y}, E\right)$ is fuzzy soft semi $T_{3}$.

Definition 5.6 Let $(X, \mathrm{~T}, E)$ be a fuzzy soft topological space, $h_{C}, g_{B}$ be disjoint fuzzy semi closed soft sets. If there exist disjoint fuzzy semi open soft sets $f_{S}$ and $f_{W}$ such that $h_{C}\left|f_{S}, g_{B}\right| f_{W}$. Then $(X, T, E)$ is called fuzzy soft semi normal space. A fuzzy soft semi normal $T_{1}$-space is called fuzzy soft semi $T_{4}$-space. 
Theorem 5.9 Let $(X, \mathrm{~T}, E)$ be a fuzzy soft topological space. Then the following are equivalent:

1- $(X, \mathrm{~T}, E)$ is fuzzy soft semi normal space.

2- For every fuzzy semi closed soft set $h_{C}$ and fuzzy semi open soft set $g_{B}$ such that $h_{C} \mid g_{B}$, there exists a fuzzy semi open soft set $f_{S}$ such that $h_{C}\left|f_{S}, \quad F S c l\left(f_{S}\right)\right| g_{B}$.

Proof.

$\mathbf{1} \rightarrow \mathbf{2}$ Let $h_{C}$ be a semi closed soft set and $g_{B}$ be a fuzzy semi open soft set such that $h_{C} \mid g_{B}$. Then $h_{C}, g_{B}^{\prime}$ are disjoint fuzzy semi closed soft sets. It follows by (1), there exist disjoint fuzzy semi open soft sets $f_{S}$ and $f_{W}$ such that $h_{C}\left|f_{S}, g_{B}^{\prime}\right| f_{W}$. Now, $f_{S} \mid f_{W}^{\prime}$, so $\operatorname{FScl}\left(f_{S}\right) \mid F S c l f_{W}^{\prime}=f_{W}^{\prime}$, where $g_{B}$ is fuzzy semi open soft set. Also, $f_{W}^{\prime} \mid g_{B}$. Hence $\operatorname{FScl}\left(f_{S}^{\prime}\right)\left|f_{W}^{\prime}\right| g_{B}$. Thus, $h_{C}\left|f_{S}, \operatorname{FScl}\left(f_{S}\right)\right| g_{B}$.

$\mathbf{2} \rightarrow \mathbf{1}$ Let $g_{A}$ and $g_{B}$ be disjoint fuzzy semi closed soft sets. Then, $g_{A} \mid g_{B}^{\prime}$. By hypothesis, there exists a fuzzy semi open soft set $f_{S}$ such that $g_{A}\left|f_{S}, \quad F S c l\left(f_{S}\right)\right| g_{B}^{\prime}$. So $g_{B}\left|\left[\operatorname{FScl}\left(f_{S}\right)\right]^{\prime}, g_{A}\right| f_{S}$ and $\left[\operatorname{FScl}\left(f_{S}\right)\right]^{\prime}\left[f_{S}=\tilde{0}_{E}\right.$, where $f_{S}$ and $\left[\operatorname{FScl}\left(f_{S}\right)\right]^{\prime}$ are fuzzy semi open soft sets. Thus, $(X, T, E)$ is fuzzy soft semi normal space.

Theorem $5.10 \mathrm{~A}$ fuzzy semi closed soft subspace $\left(Y, \mathrm{~T}_{Y}, E\right)$ of a fuzzy soft semi normal space $(X, \mathrm{~T}, E)$ is fuzzy soft semi normal.

Proof. Let $g_{A}$ and $g_{B}$ be disjoint fuzzy semi closed soft sets in $\mathrm{T}_{Y}$. Then $g_{A}$ and $g_{B}$ are disjoint fuzzy semi closed soft sets in $\mathrm{T}$. Since $(X, \mathrm{~T}, E)$ is fuzzy soft semi normal. Then there exist disjoint fuzzy semi open soft sets $f_{S}$ and $f_{W}$ in $\mathrm{T}$ such that $g_{A}\left|f_{S}, g_{B}\right| f_{W}$. It follows that $h_{E}^{Y}\left[f_{S}\right.$ and $h_{E}^{Y}\left[f_{W}\right.$ are disjoint fuzzy semi open soft sets in $\mathrm{T}_{Y}$ such that $g_{e} \tilde{\in} h_{E}^{Y}\left[f_{S}\right.$ and $k_{E} \mid h_{E}^{Y}\left[f_{W}\right.$. Therefore, $\left(Y, \mathrm{~T}_{Y}, E\right)$ is fuzzy soft semi normal.

Theorem 5.11 Let $\left(X, \mathrm{~T}_{1}, E\right)$ and $\left(Y, \mathrm{~T}_{2}, K\right)$ be fuzzy soft topological spaces and $f_{p u}: S S(X)_{E} \rightarrow S S(Y)_{K}$ be a fuzzy soft function which is surjective, injective, fuzzy irresolute soft and fuzzy irresolute open soft. If $\left(X, \mathrm{~T}_{1}, E\right)$ is soft semi normal space, then $\left(Y, \mathrm{~T}_{2}, K\right)$ is also fuzzy soft semi normal space.

Proof. Let $f_{A}, g_{B}$ be disjoint fuzzy semi closed soft sets in $Y$. Since $f_{p u}$ is fuzzy irresolute soft, then $f_{p u}^{-1}\left(f_{A}\right)$ and $f_{p u}^{-1}\left(g_{B}\right)$ are fuzzy semi closed soft set in $X$ such that $f_{p u}^{-1}\left(f_{A}\right)\left[f_{p u}^{-1}\left(g_{B}\right)=f_{p u}^{-1}\left[f_{A} \int_{g_{B}}\right]=f_{p u}^{-1}\left[\tilde{0}_{K}\right]=\tilde{0}_{E}\right.$ from Theorem 2.3. By hypothesis, there exist disjoint fuzzy semi open soft sets $k_{C}$ and $h_{D}$ in $X$ such that $f_{p u}^{-1}\left(f_{A}\right) \mid k_{C}$ and $f_{p u}^{-1}\left(g_{B}\right) \mid h_{D}$. It follows that $f_{A}=f_{p u}\left[f_{p u}^{-1}\left(f_{A}\right)\right] \mid f_{p u}\left(k_{C}\right)$, $g_{B}=f_{p u}\left[f_{p u}^{-1}\left(g_{B}\right)\right] \mid f_{p u}\left(h_{D}\right)$ from Theorem 2.3 and 
$f_{p u}\left(k_{C}\right)\left[f_{p u}\left(h_{D}\right)=f_{p u}\left[k_{C}\left(h_{D}\right]=f_{p u}\left[\tilde{0}_{E}\right]=\tilde{0}_{K}\right.\right.$ from Theorem 2.3. Since $f_{p u}$ is fuzzy irresolute open soft function. Then $f_{p u}\left(k_{C}\right), f_{p u}\left(h_{D}\right)$ are fuzzy semi open soft sets in $Y$ . Thus, $\left(Y, \mathrm{~T}_{2}, K\right)$ is fuzzy soft semi normal space.

\section{Conclusion}

Topology is an important and major area of mathematics and it can give many relationships between other scientific areas and mathematical models. Recently, many scientists have studied the soft set theory, which is initiated by Molodtsov [25] and easily applied to many problems having uncertainties from social life. In the present work, we have continued to study the properties of fuzzy soft topological spaces. We introduce the some new concepts in fuzzy soft topological spaces such as fuzzy semi open soft sets, fuzzy semi closed soft sets, fuzzy semi soft interior, fuzzy semi soft closure and fuzzy semi separation axioms and have established several interesting properties. Since the authors introduced topological structures on fuzzy soft sets $[8,15$, 35], so the semi topological properties, which introduced by Kandil et al.[17], is generalized here to the fuzzy soft sets which will be useful in the fuzzy systems. Because there exists compact connections between soft sets and information systems [29,37], we can use the results deducted from the studies on fuzzy soft topological space to improve these kinds of connections. We hope that the findings in this paper will help researcher enhance and promote the further study on fuzzy soft topology to carry out a general framework for their applications in practical life.

\section{References}

[1] B. Ahmad and A. Kharal, Mappings of fuzzy soft classes, Adv. Fuzzy Syst. (2009), Art. ID 407890, 6 pp.

[2] B. Ahmad and A. Kharal, Mappings of soft classes, New Math. Nat. Comput. 7 (3) (2011) 471-481.

[3] B. Ahmad and A. Kharal, On fuzzy soft sets, Adv. Fuzzy Syst. (2009) 1-6.

[4] M. I. Ali, F. Feng, X. Liu, W. K. Min and M. Shabir, On some new operations in soft set theory, Computers and Mathematics with Applications 57 (2009) 1547-1553.

[5]A. M. Aminpour and M. Seilani, Compact topological semigroups associated with oids , J. Math. Computer Sci. 12 (3) (2014) 219-234.

[6] S. Atmaca and I.Zorlutuna, On fuzzy soft topological spaces, Annals of Fuzzy Mathematics and Informatics 5 (2013) 377-386.

[7] A. Aygunoglu and H. Aygun, Introduction to fuzzy soft groups, Computers and Mathematics with Applications 58 (2009) 1279-1286.

[8] Bakir Tanay and M. Burcl Kandemir, Topological structure of fuzzy soft sets, Computer and mathematics with applications (61) (2011) 2952-2957.

[9] N. Cagman, F. Citak and S. Enginoglu, Fuzzy parameterized fuzzy soft set theory and its applications, Turkish Journal of Fuzzy Systems 1 (1) (2010) 21-35. 
[10] N. Cagman and S. Enginoglu, Soft set theory and uni-Fint decision making, European Journal of Operational Research 207 (2010) 848-855.

[11] C. L. Change, Fuzzy topological spaces, J. Math. Anal. Appl., 24 (1968) 182-190.

[12]Eshagh Hosseinpour, T-rough fuzzy subgroups of groups, J. Math. Computer Sci. 12 (3) (2014) 186-195.

[13] Haci Aktas and Naim Cagman, Soft sets and soft groups, Innformation science 177 (2007) 2726-2735.

[14]M. Jain and M. P. S. Bhatia, A rough set based approach to classify node behavior in mobile ad hoc networks, J. Math. Computer Sci. 10 (2) (2014) 64-78.

[15] Jianyu Xiao, Minming Tong, Qi Fan and Su Xiao, Generalization of Belief and Plausibility Functions to Fuzzy Sets, Applied Mathematics Information Sciences 6 (2012), 697-703.

[16] A.Kandil, O. A. E. Tantawy, S. A. El-Sheikh and A. M. Abd El-latif, $\gamma$-operation and decompositions of some forms of soft continuity in soft topological spaces, Annals of Fuzzy Mathematics and Informatics 7 (2014) 181-196.

[17] A.Kandil, O. A. E. Tantawy, S. A. El-Sheikh and A. M. Abd El-latif, Soft semi separation axioms and irresolute soft functions, Annals of Fuzzy Mathematics and Informatics 8 (2014) 305-318.

[18] D. V. Kovkov, V. M. Kolbanov and D. A. Molodtsov, Soft sets theory-based optimization, Journal of Computer and Systems Sciences Finternational 46 (6) (2007) 872-880.

[19] F. Lin, Soft connected spaces and soft paracompact spaces, International Journal of Mathematical Science and Engineering, 7 (2) (2013) 1-7.

[20] J. Mahanta and P.K. Das, Results on fuzzy soft topological spaces, arXiv:1203.0634v1,2012.

[21] P. K. Maji, R. Biswas and A. R. Roy, Fuzzy soft sets, Journal of Fuzzy Mathematics 9 (3) (2001) 589-602.

[22] P. K. Maji, R. Biswas and A. R. Roy, intuitionistic fuzzy soft sets, Journal of Fuzzy Mathematics 9 (3) (2001) 677-691.

[23] P. K. Maji,R. Biswas and A. R. Roy, Soft set theory, Computers and Mathematics with Applications 45 (2003) 555-562.

[24] P. Majumdar and S. K. Samanta, Generalised fuzzy soft sets, Computers and Mathematics with Applications 59 (2010) 1425-1432.

[25] D. A. Molodtsov, Soft set theory-firs tresults, Computers and Mathematics with Applications 37 (1999) 19-31.

[26] D.Molodtsov, V. Y. Leonov and D. V. Kovkov, Soft sets technique and its application, Nechetkie Sistemy i Myagkie Vychisleniya 1 (1) (2006) 8-39.

[27] A. Mukherjee and S. B. Chakraborty, On Fintuitionistic fuzzy soft relations, Bulletin of Kerala Mathematics Association 5 (1) (2008) 35-42.

[28] B. Pazar Varol and H. Aygun, Fuzzy sot topology, Hacettepe Journal of Mathematics and Statistics 41 (3) (2012) 407-419.

[29] D. Pei and D. Miao, From soft sets to information systems, in: X. Hu, Q. Liu, A. Skowron, T. Y. Lin, R. R. Yager, B. Zhang (Eds.), Proceedings of Granular Computing, in: IEEE, vol.2, 2005, pp. 617-621. 
[30]H. Rahimpoor, A. Ebadian, M. Eshaghi Gordji and A. Zohri, Fixed point theory for generalized quasi-contraction Maps in modular metric spaces, J. Math. Computer Sci. 10 (1) (2014) 47-53.

[31] S. Roy and T. K. Samanta, A note on fuzzy soft topological spaces, Annals of Fuzzy Mathematics and informatics 3 (2) (2012) 305-311.

[32] S. Roy and T. K. Samanta, An introduction to open and closed sets on fuzzy topological spaces, Annals of Fuzzy Mathematics and Informatics, 2012.

[33] M. Shabir and M. Naz, On soft topological spaces, Comput. Math. Appl. 61 (2011) 1786-1799.

[34] J. K. Syed and L. A. Aziz, Fuzzy Inventory Model without Short-ages Using Signed Distance Method, Applied Mathematics Information Sciences 1 (2007) 203-209.

[35] B. Tanay and M. B. Kandemir, Topological structure of fuzzy soft sets, Computer and Math. with appl. 61 (2011) 412-418.

[36] Won Keun Min, A note on soft topological spaces, Computers and Mathematics with Applications 62 (2011) 3524-3528.

[37] Z. Xiao, L. Chen, B. Zhong and S. Ye, Recognition for soft information based on the theory of soft sets, in: J. Chen (Ed.), Proceedings of ICSSSM-05, vol. 2, IEEE, 2005, pp. 1104-1106.

[38] Yong Chan Kim and Jung Mi Ko, Fuzzy G-closure operators, commun Korean Math. Soc. 18(2)(2008), 325-340.

[39] L. A. Zadeh, Fuzzy sets, Information and Control 8 (1965) 338-353.

[40] Y. Zou and Z. Xiao, Data analysis approaches of soft sets under incomplete information, Knowledge-Based Systems 21 (2008) 941-945. 